\title{
Dyslipidemia and maternal obesity: Prematurity and neonatal prognosis
}

\author{
Raquel Fleig ${ }^{5}$, Jean Carl Silva ${ }^{6}$

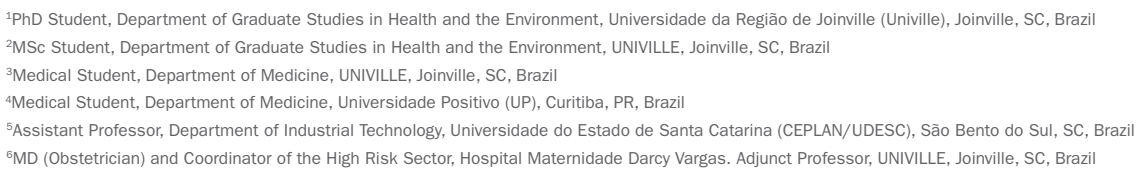

Iramar Baptistella do Nascimento ${ }^{1 *} \odot$, Guilherme Dienstmann², Matheus Leite Ramos de Souza ${ }^{3}$, Thiago Ribeiro e Silva ${ }^{4}$,

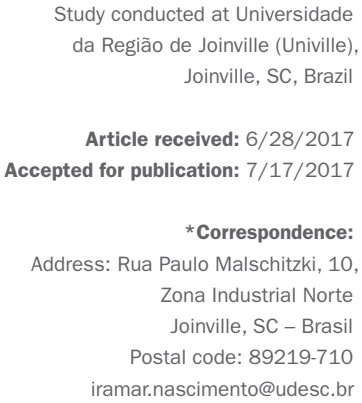

Article received: 6/28/2017 Accepted for publication: $7 / 17 / 2017$

*Correspondence: Address: Rua Paulo Malschitzki, 10, Zona Industrial Norte Joinville, SC - Brasil Postal code: 89219-710 iramar.nascimento@udesc.br

\section{SUMMARY}

Objective: To identify the changes caused by dyslipidemia and obesity in pregnancy suggesting causes for premature birth, and the prognosis for the newborn.

Method: Systematic review based on the Medline, Lilacs, Embase and Cochrane library databases between 1996 and 2016. The search for studies included the following keywords: "dyslipidemia, pregnancy, obesity, preterm birth." A protocol was programmed and a protocol for inclusion/exclusion of studies was implemented.

Results: Of the 5,789 articles initially selected between March 1996 and July 2016 , only 32 were in accordance with the established criteria. Of these, $28.12 \%$ discussed risk factors of prematurity; $37.50 \%$, metabolic alterations and gestational dyslipidemia; $21.87 \%$, dyslipidemic complications in preterm birth; and $12,50 \%$, lipid metabolism, glycemic and placental transfer.

Conclusion: There is a reduced adaptation of obese pregnant women to the metabolic changes of gestation. This favors dyslipidemic intercurrences in the mother, which, directly or indirectly, suggests the occurrence of premature births and high lipid transfer to the fetus. Therefore, preterm newborns, whose mothers were dyslipidemic during pregnancy, have greater risk of epicardial fat, both in early (first year of life) and in later (adult) phases of life.

Keywords: Dyslipidemias. Pregnancy. Obesity. Premature Birth.

\section{INTRODUCTION}

Prematurity results from multifactorial and unpredictable circumstances in all social classes and locations, and implies better understanding of perinatal causes and outcomes. Among other comorbidities, the relationships between a preterm birth and the newborn's low weight and a prognosis of growth deficit are evident. ${ }^{1}$ A study carried out in the last decade emphasizes that prematurity increases the likelihood of developing cardiovascular diseases and other chronic diseases. ${ }^{2}$ Still, despite a rather recent interest in it, a reduced number of papers on the subject and its specific etiological factors, a higher survival rate of premature infants favored by the advancement in health technologies is suggested. ${ }^{3}$
Dyslipidemia is characterized by abnormal levels of cholesterol and triglycerides, which generally increases the overweight rates and, when associated with pregnancy, is a worrisome change that can increase adverse pregnancy outcomes. ${ }^{3}$ Among the various gestational outcomes, a study revealed that, in the year 2000, premature births accounted for $28 \%$ of neonatal deaths in 193 countries. ${ }^{4}$ Risk factors for prematurity are relevant elements pending further research. ${ }^{5,6}$

Accordingly, it is of the utmost importance that we understand the relationships between dyslipidemia and obesity with prematurity and the specificities and peculiarities regarding changes during the gestational period, such as the isolated increase in serum cholesterol and 
triglycerides, and mixed hyperlipidemic changes. ${ }^{6,7} \mathrm{How}-$ ever, during pregnancy, physical, psychological and social behavior are altered due to the special conditions of the pregnant state, which is neither physiologically normal neither clinically abnormal. ${ }^{8,9}$ Hence, based on scientific publications from 1996 to 2016, our study was aimed at identifying the changes brought about by dyslipidemia and obesity that may suggest the causes of premature birth and the prognosis for the newborn.

\section{Method}

\section{Identification of studies}

We undertook a selective review of the literature between March 1996 and July 2016 on which are the changes caused by dyslipidemia and obesity that suggest causes of premature birth and their coadjuvancy regarding the prognosis for the newborn. At first, we developed a protocol establishing the sources to be searched, languages, keywords and dates of publication over the past 20 years. Among methodological criteria, we prioritized sample size and the most recent years of publication. Papers published between 1996 and 2016 were extracted from the Medline, Lilacs, Embase and Cochrane databases. We selected the keywords "dyslipidemias," "pregnancy," "obesity" and "premature birth," which we checked against the DeCS Descritores em Ciências da Saúde (Descriptors in Health Sciences), associated with the Boolean operators "AND" and "OR," published in Portuguese, English or Spanish.

\section{Inclusion criteria}

The papers to be evaluated and/or selected for our study should present research results on obesity and dyslipidemia in pregnancy and the predisposing factors therefore suggestive of the causes of prematurity and its relationship with the prognosis for the newborn (NB). Our selection included clinical trials; cross-sectional studies; cohort studies; case-control studies; epidemiological studies; and bibliographic reviews. In clinical trials, cohort studies; and casecontrol studies, in addition to the abovementioned criteria, we prioritized studies having a longer follow-up period. Literature reviews and epidemiological studies needed to be related to the subject and goal of our research. All members of our group participated in selecting the articles. Whenever there were any divergences regarding two or more articles, the scholars then analyzed the study in its entirety, discussing and debating it at previously scheduled meetings.

\section{Population}

Overweight pregnant women with a dyslipidemic profile, aged 18 years or older, and preterm NBs.

\section{Exclusion criteria}

Non-relevant scientific articles dealing with dyslipidemias in non-gestational conditions or articles published in languages other than Portuguese, English or Spanish.

Selection process of theoretical references for systematic reviews From the initial selection of publications, together with the chosen databases and the proposed criteria, we obtained a total of 5,789 articles compatible with the proposed subject. Subsequently, we proceeded to select the references for systematic reviews (Figure 1) by following the exclusion steps: identification of repeated studies; reading of titles; reading of abstracts and methodological analysis; and identification of studies having no correlation with our study's goal. After double-checking the criteria and acquiring the articles to be used, we reorganized the number of selected studies into four topics: prematurity outcomes; metabolic changes and gestational dyslipidemia; dyslipidemic complications during preterm birth; lipid and glycemic metabolism and placental transfer.

\section{Results and Discussion}

In the systematic review, after applying the selection criteria mentioned above, we obtained 32 scientific studies, of which $28.12 \%$ ( $n=9$ ) were on prematurity outcomes; $37.50 \%(\mathrm{n}=12)$ on metabolic changes and gestational dyslipidemia; $21.87 \%(\mathrm{n}=7)$ on dyslipidemic complications during preterm birth; and $12.50 \%(\mathrm{n}=4)$ on lipid and glycemic metabolism and placental transfers. The scientific studies that met the selection criteria and were used in our study are shown in Table 1. Consecutively, we developed a schematic model for lipid alteration from tumor necrosis factor alpha (TNF- $\alpha$ ), according to Figure 2. Figure 3 depicts the representation of an artery with dyslipidemia.

\section{Prematurity outcomes}

As from the last decades, prematurity has been considered the main cause of infant mortality and some important pulmonary, neurocognitive and ophthalmologic morbidities. Due to these factors, it was recognized as a serious public health problem. ${ }^{10,11}$ Studies on prematurity indicated high neonatal morbidity and mortality rates and the occurrence of sequelae of varied natures. ${ }^{4,10}$

Some authors showed the associations between prematurity and the development of some complications related to glucose intolerance and dyslipidemias, both in children and in preterm-born adults who presented with increased blood pressure and insulin resistance at 30 years of age. ${ }^{11}$ 


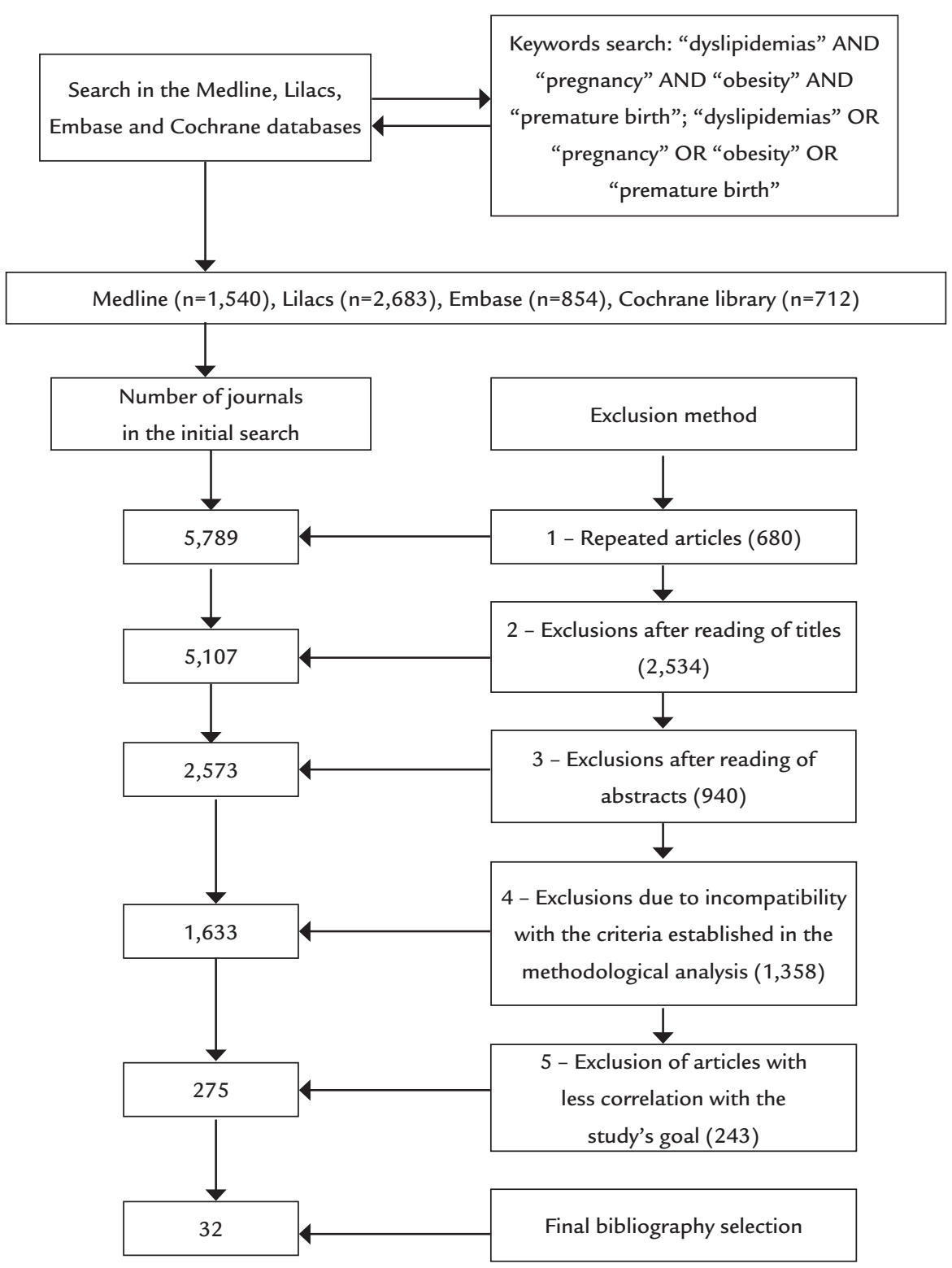

FIGURE 1 Flowchart of the activities of the selection process in the years 1996-2016.

\section{TABLE 1 Studies that met the selection criteria (1996-2016).}

\begin{tabular}{|c|c|c|c|}
\hline Authors & Type of study & Year of publication & Population \\
\hline Pessoa et al. ${ }^{1}$ & Retrospective cohort & 2015 & Newborns \\
\hline Bassareo et al. ${ }^{2}$ & Prospective cohort & 2016 & Newborns \\
\hline Castaño et al. ${ }^{3}$ & Retrospective cohort & 2013 & Pregnant women \\
\hline Lawn et al. ${ }^{4}$ & Review study & 2010 & Newborns \\
\hline Herrera et al. ${ }^{5}$ & Review study & 2006 & Pregnant women \\
\hline Nucci et al. ${ }^{6}$ & Retrospective cohort & 2001 & Pregnant women \\
\hline Stulbach et al. ${ }^{7}$ & Retrospective cohort & 2007 & Pregnant women \\
\hline Oliveira et al. ${ }^{8}$ & Cross-sectional study & 2012 & Pregnant women \\
\hline Cheung et al. ${ }^{9}$ & Prospective cohort & 2004 & Newborns \\
\hline
\end{tabular}


TABLE 1 (Cont.) Studies that met the selection criteria (1996-2016).

\begin{tabular}{|c|c|c|c|}
\hline Authors & Type of study & Year of publication & Population \\
\hline Lorena et al. ${ }^{10}$ & Cross-sectional study & 2009 & Newborns \\
\hline Dalziel et al. ${ }^{11}$ & Prospective cohort & 2007 & Newborns \\
\hline Tomashek et al. ${ }^{12}$ & Retrospective cohort & 2006 & Newborns \\
\hline Shapiro-Mendoza et al. ${ }^{13}$ & Retrospective cohort & 2008 & Newborns \\
\hline Machado et al. ${ }^{14}$ & Retrospective cohort & 2016 & Pregnant women \\
\hline Hentges et al. ${ }^{15}$ & Prospective cohort & 2010 & Newborns \\
\hline Luz et al. ${ }^{16}$ & Cross-sectional study & 2008 & Pregnant women \\
\hline Oliveiros Donohue et al. ${ }^{17}$ & Retrospective cohort & 2003 & Newborns \\
\hline Ywaskewycz Benitez et al. ${ }^{18}$ & Case-control & 2010 & Pregnant women \\
\hline Ghio et al. ${ }^{19}$ & Review study & 2011 & Pregnant women \\
\hline Mangucci et al. ${ }^{20}$ & Prospective cohort & 2014 & Pregnant women \\
\hline Oliveira et al. ${ }^{21}$ & Case-control & 2016 & Pregnant women \\
\hline Mudd et al. ${ }^{22}$ & Prospective cohort & 2012 & Pregnant women \\
\hline Adamo et al. ${ }^{23}$ & Clinical trial & 2013 & Pregnant women \\
\hline Jelliffe-Pawlowski el al. ${ }^{24}$ & Retrospective cohort & 2014 & Pregnant women \\
\hline Joy et al. ${ }^{25}$ & Case-control & 2009 & Pregnant women \\
\hline Berkowitz et al. ${ }^{26}$ & Retrospective cohort & 1998 & Newborns \\
\hline Merzouk et al. ${ }^{27}$ & Prospective cohort & 2000 & Newborns \\
\hline Sebire et al. ${ }^{28}$ & Cross-sectional study & 2001 & Pregnant women \\
\hline Higa et al. ${ }^{29}$ & Review study & 2013 & Pregnant women \\
\hline Crume et al. ${ }^{30}$ & Prospective cohort & 2015 & Pregnant women \\
\hline Watkins et al. ${ }^{31}$ & Case-control & 2003 & Pregnant women \\
\hline Hull et al. ${ }^{32}$ & Review study & 2008 & Pregnant women \\
\hline
\end{tabular}

Tomashek et al. ${ }^{12}$ highlighted the group of borderline preterm newborns, i.e. the group of late preterm newborns (L-PTNB) defined as premature with a gestational age (GA) between 34 complete weeks and 36 weeks and 6 days. The researchers identified a percentage of deaths among preterm infants born at 36 weeks twice as high as compared to that among infants born at 34 weeks. Another study revealed a seven-fold higher risk of morbidity among L-PTNB when compared to term newborns (TNB). ${ }^{13}$

Nevertheless, it is noteworthy that the L-PTNB group has begun to be studied more systematically as from the 2000s, with a significant increase in morbidity and mortality and associated risks related to respiratory pathologies, thermal instability, a greater number of neurological alterations and lower Apgar scores. ${ }^{13,14}$ Even though there are studies identifying a diversity of risks related to neonatal morbidity and mortality and high-incidence rates of prematurity-related sequelae of varied natures, both L-PTNB and their diversity of high risk when compared to TNB deserved our special consideration in this systematic review. ${ }^{11,13,15}$ It is a well-known fact that the main cause of maternal death is complications caused by high blood pressure during pregnancy or at the time of delivery, as well as hemorrhages and other morbidities. ${ }^{16,17}$

However, studies on birth weight and changes in arterial blood pressure throughout the child's life were more unanimous in investigating possible risks, especially when compared with studies on GA and current infant weight.

\section{Metabolic changes and gestational dyslipidemia}

Despite the fact that most studies focused on gestational concerns, which correspond to several factors arising from dietary imbalance and caloric expenditure, the relationship between physiological changes and lipid and glycemic metabolism during pregnancy deserved special attention in the studies. ${ }^{3,6,7}$ It was thus found that, over the course of gestation, adipose tissue and its lipolytic activity cause an increase in serum levels of glycerol being converted into glucose in the liver, which in turn is gradually made available to the fetus. ${ }^{6}$

During pregnancy, investigators found an increase in the levels of high-density lipoprotein cholesterol (HDL-c) and very-low-density lipoprotein cholesterol (VLDL), as well as in the concentrations obtained from lipid and lipoprotein 


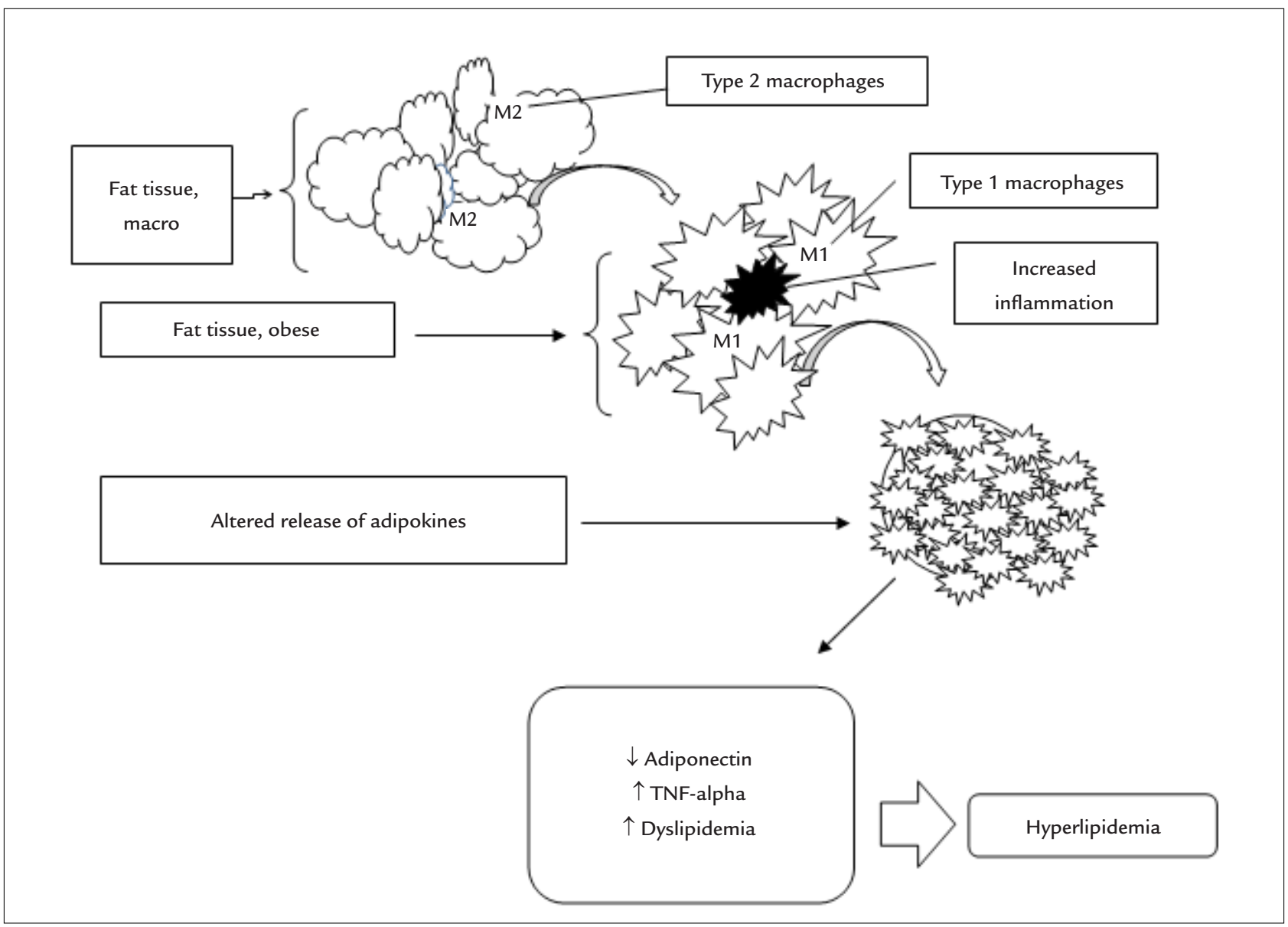

FIGURE 2 Schematic model of tumor necrosis factor alpha (TNF- $\alpha$ ) altering the lipid profile.

measurements by a comparative study with non-pregnant women. That study provided guidelines as to when a physiological indicator may be associated with pregnancy diseases and/or disorders..$^{18}$ Ghio et al. ${ }^{19}$ observed a gradual increase in the triglycerides, total cholesterol (TC), VLDL and HDL-c lipid patterns from the $12^{\text {th }}$ week of pregnancy, especially in the second and third trimesters in response to estrogen stimulation and insulin resistance, as well as an increase in the risk of pre-eclampsia and premature birth.

In previous scientific studies including overweight and obese women, the hypotheses and suggestions pertaining to a consecutive increase in dyslipidemic changes and gestational complications are notorious. The studies conducted by Callegari et al. ${ }^{20}$ in an attempt to identify cardiometabolic risks comparing normal-weight pregnant women with overweight pregnant women found an increase in the levels of triglycerides, TC, VLDL and low-density lipoprotein cholesterol (LDL-c) in both groups. Yet, the HDL-c levels remained unchanged in normalweight pregnant women, in contrast with the significantly low levels found in overweight pregnant women.
In carrying out this study, we conclude that, among pregnant women with an adequate weight, ancestry or descent on HDL-c parameters showed diversities in some scientific studies. The alternating patterns allow for suggestions for pathological indicators, including prematurity and future cardiac events for the newborn. ${ }^{21}$

Hence, with respect to each variable analyzed, these correlations make it possible for the reader to identify the events caused by maternal overweight and to deem dyslipidemic alternations as indicators of complications, such as predisposition to high systemic arterial blood pressure, cardiometabolic events and the outcomes of a premature delivery. ${ }^{18,22,23}$

\section{Dyslipidemic complications in preterm birth}

Even though changes in pregnancy are evident, the likelihood of a clinical and physiological imbalance during the gestational period is indisputable. It is therefore essential that pregnant women be followed up and have their weight controlled to ensure both maternal and fetal health. ${ }^{1,3}$ Mudd et al. ${ }^{22}$ demonstrated an existing relationship between 


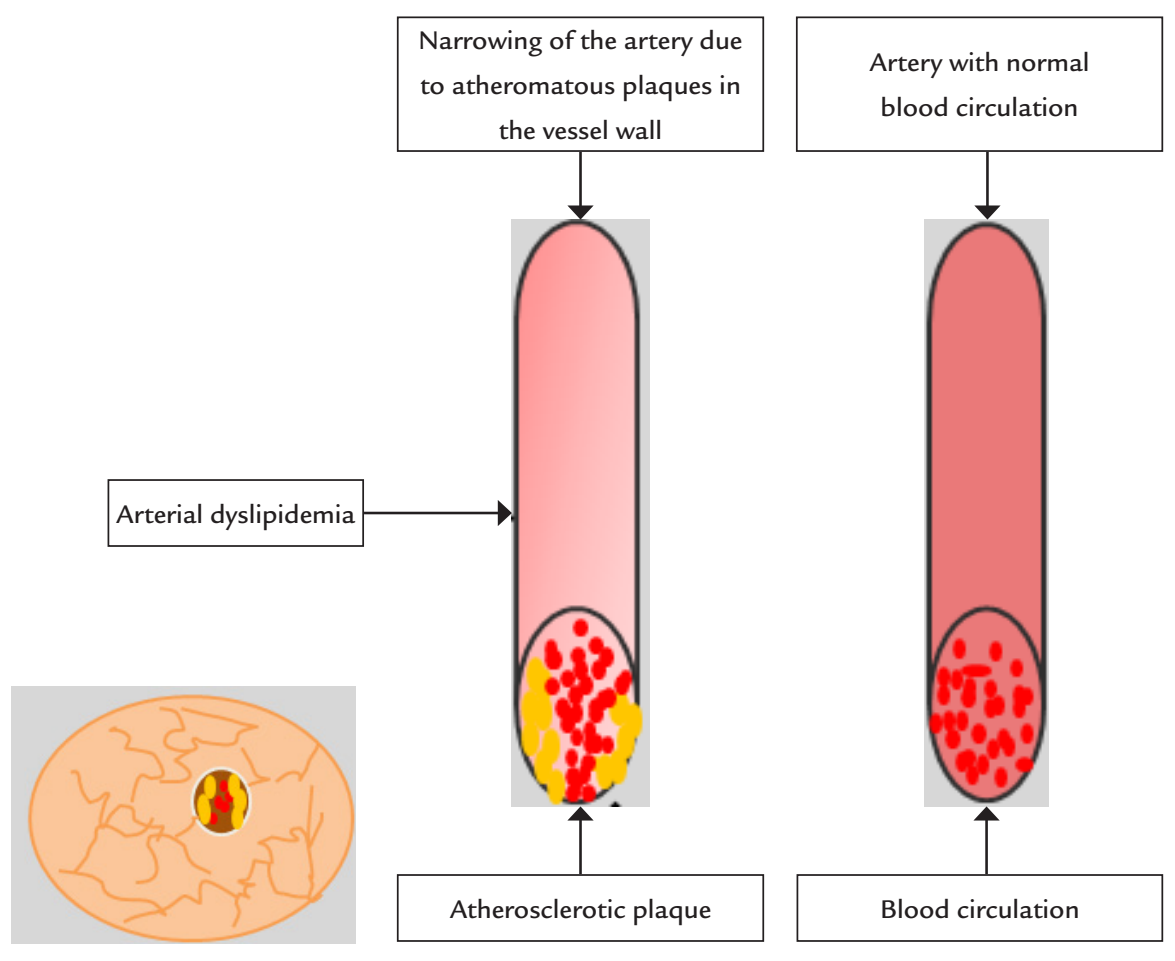

FIGURE 3 Schematic model of an artery with dyslipidemia.

lipid levels and the risk of premature birth complications. According to the authors, low TC, LDL-c and HDL-c values are associated with a moderately increased risk of medically indicated preterm deliveries, whereas high TC, LDL-c and triglycerides are associated with spontaneous preterm deliveries.

There is an established link between TNF- $\alpha$ and the release of lipids by adipocytes, i.e. TNF- $\alpha$ being induced by lipolysis. A study revealed that, midway through gestation, an increase in TNF- $\alpha$ and lipid levels can lead to the development of gestational hyperlipidemia. It also suggested an interrelationship involving TNF- $\alpha$, hyperlipidemia and a preterm delivery. ${ }^{24}$ Another study emphasized the rates of complications attributed to maternal obesity, such as hyperglycemia and hyperlipidemia, with complications in materno-fetal and neonatal outcomes. This leads us to deduce that obesity and dyslipidemic alterations may place a fullterm pregnancy in jeopardy. ${ }^{25}$ On the other hand, so researchers found an inconsistency in the association between obesity and preterm delivery, due to the fact that some pregnant women presented with obesity-related diseases. ${ }^{26}$

The relationship between dyslipidemia and risks of materno-fetal complications is significantly independent of maternal obesity. In the studies by Merzouk et al., ${ }^{27}$ the increase in fetal lipid levels showed an association with the metabolic levels of poorly-controlled diabetic mothers and consecutively their macrosomic newborns had increased values of all serum lipids and in their apolipoprotein and lipoprotein lipid levels.

Regarding the possibility of prematurity being caused by dyslipidemic and hyperglycemic changes and overweight during pregnancy, we must bear in mind that the association between maternal obesity and preterm birth is controversial, with particularities yet to be uncovered. In other words, while some studies reported high risks or a diminished relationship, other studies found no correlation at all. ${ }^{22,25,26,28}$ Nevertheless, some researchers state that prematurity is independent of maternal hyperglycemia, ${ }^{5}$ suggesting thus that it is more closely associated with maternal dyslipidemia.

\section{Lipid and glycemic metabolism and placental transfers}

The placenta plays a key role in transferring lipid radicals to the fetal compartment, which can be consecutively affected by maternal diseases associated with the impairment of lipid homeostasis. ${ }^{29}$ Therefore, the role of long chain polyunsaturated fatty acids (LC-PUFA) becomes emphasized: the presence of lipoprotein receptors in the placenta promotes their uptake, which causes fatty acids to be metabolized and diffused to the fetus. ${ }^{6}$ 
A study deserving special mention is an observational epidemiological study on pregnant women indicating certain proteins that indirectly influence neonatal adiposity, such as leptin and adiponectin, two proteins that can be stimulated when there is maternal insulin resistance, thereby altering the mechanisms of placental transport. ${ }^{30}$ According to the scientific literature, metabolism during pregnancy is related to the production of ketone bodies being consecutively used by the fetus for fatty acid synthesis. This emphasizes the fact that the contribution of maternal fatty acids to the fetus and the possible bioenergetic conversions can be either intensified or restricted, which can cause serious problems to fetal organs and tissues in either case. ${ }^{6,31}$

With regard to glycemic and lipid metabolism and placental transfer, a study showed that pathophysiological problems can be related to materno-fetal transport mechanisms. Similarly, the influence from the mother's lipid catabolism can also be involved, which can directly or indirectly favor or limit the transfer of lipids to the fetus. ${ }^{32}$

In this context, dyslipidemia during pregnancy and the parameters of lipid transfer from mother to fetus have been scientifically shown to be influenced by placental hormones affecting both glucose and lipid metabolism to ensure that the fetus has a sufficient supply of essential nutrients for its development. ${ }^{5}$ However, as far as scientific results and/or parameters we surveyed are concerned, metabolic adaptations are notoriously less flexible among obese pregnant women than they are in normal-weight pregnant women, which may impair the materno-fetal transport mechanism.

Our systematic review has some limitations, such as difficulties in finding factors relating dyslipidemia to prematurity in the studies with the population defined according to the initial protocol, given that we aimed at investigating scientific studies of populations with human beings. Another limiting factor was the small number of epidemiological studies on the particularities involving causes and risks of prematurity and consecutively the abbreviated follow-up on the possible dyslipidemic outcomes among newborns. Conversely, one strength of our study was the number of studies with dyslipidemic obese pregnant women, which greatly allowed for comparative analyses and/or suggestions as to prognoses according to the statistical results.

\section{Conclusion}

There is a reduced adaptation of obese pregnant women to the metabolic changes of gestation. This favors dyslipidemic intercurrences in the mother, which, directly or indirectly, suggests the occurrence of premature births and high lipid transfer to the fetus. Therefore, preterm newborns, whose mothers were dyslipidemic during pregnancy, have greater risk of epicardial fat, both in early (first year of life) and in later (adult) phases of life.

\section{Resumo}

Dislipidemia e obesidade materna: prematuridade e prognóstico neonatal

Objetivo: Identificar as alterações provocadas pela dislipidemia e pela obesidade na gestação que sugerem causas de partos prematuros e o prognóstico para o recém-nascido.

Método: Revisão sistemática nas bases de dados Medline, Lilacs, Embase e da biblioteca Cochrane entre os anos de 1996 e 2016. O processo de seleção ocorreu a partir dos descritores dislipidemia, gravidez, obesidade, nascimento prematuro. Um protocolo foi programado, havendo uma etapa seletiva de inclusão/exclusão das pesquisas.

Resultados: Dentre os 5.789 artigos inicialmente selecionados entre março e julho de 2016, somente 32 estavam de acordo com os critérios estabelecidos. Desses, 28,12\% focavam nos fatores de risco da prematuridade; $37,50 \%$, em alterações metabólicas e dislipidemia gestacional; $21,87 \%$, em intercorrências dislipidêmicas no parto prematuro; $12,50 \%$, em metabolismo lipídico, glicêmico e transferências pela placenta.

Conclusão: Existe uma menor adaptação da gestante obesa às mudanças metabólicas da gestação, favorecendo intercorrências dislipidêmicas na mãe, o que, direta ou indiretamente, sugere a ocorrência de partos prematuros e uma elevada transferência de lipídios para o feto. Portanto, recém-nascidos prematuros de mães dislipidêmicas durante a gravidez apresentam maior risco de desenvolver gordura epicárdica tanto na fase precoce (primeiro ano de vida) quanto na tardia (vida adulta).

Palavras-chave: Dislipidemias. Gravidez. Obesidade. Nascimento Prematuro.

\section{References}

1. Pessoa TAO, Martins CBG, Lima FCA, Gaíva MAM. O crescimento e desenvolvimento frente à prematuridade e baixo peso ao nascer. Av Enferm. 2015;33(3):401-11.

2. Bassareo PP, Fanos V, Puddu M, Marras S, Mercuro G. Epicardial fat thickness, an emerging cardiometabolic risk factor, is increased in young adults born preterm. J Dev Orig Health Dis. 2016;7(4):369-73.

3. Bautista-Castaño I, Henriquez-Sanchez P, Alemán-Perez N, Garcia-Salvador JJ, Gonzales-Quesada A, García-Hernández JA, et al. Maternal obesity in early pregnancy and risk of adverse outcomes. PLoS One. 2013;8(11):e80410.

4. Lawn JE, Wilczynska-Ketende K, Cousens SN. Estimating the causes of 4 million neonatal deaths in the year 2000. Int J Epidemiol. 2006;35(3):706-18. 
5. Beardsall K, Vanhaesebrouck S, Ogilvy-Stuart AL, Vanhole C, Palmer CR, Ong $\mathrm{K}$, et al. Prevalence and determinants of hyperglycemia in very low birth weight infants: cohort analyses of the NIRTURE study. J Pediatr. 2010;157(5):715-9.

6. Herrera E, Amusquivar E, López-Soldado I, Ortega H. Maternal lipid metabolism and placental lipid transfer. Horm Res. 2006;65(Suppl 3):59-64.

7. Bertoldi Nucci L, Bartholow Duncan B, Serrate Mengue S, Branchtein L, Shimidt MI, Fleck ET. Assessment of weight gain during pregnancy in general prenatal care services in Brazil. Cad Saude Publica. 2001;17(6):1367-74.

8. Oliveira MR, Dessen MA. Alterações na rede social de apoio durante a gestação e o nascimento de filhos. Estud Psicol. 2012;29(1):81-8.

9. Cheung YF, Wong KY, Lam BC, Tsoi NS. Relation of arterial stiffness with gestational age and birth weight. Arch Dis Child. 2004;89(3):217-21.

10. Lorena SHT, Brito JMS. Estudo retrospectivo de crianças pré-termo no Ambulatório de Especialidades Jardim Peri-Peri. Arq Bras Oftalmol. 2009;72(3):360-4.

11. Dalziel SR, Parag V, Rodgers A, Harding JE. Cardiovascular risk factors at age 30 following pre-term birth. Int J Epidemiol. 2007;36(4):907-15.

12. Tomashek KM, Shapiro-Mendoza CK, Weiss J, Kotelchuck M, Barfield W, Evans S, et al. Early discharge among late preterm and term newborns and risk of neonatal morbidity. Semin Perinatol. 2006;30(2):61-8.

13. Shapiro-Mendoza CK, Tomashek KM, Kotelchuck M, Barfield W, Nannini A, Weiss J, et al. Effect of late-preterm birth and maternal medical conditions on newborn morbidity risk. Pediatrics. 2008;121(2):e223-32.

14. Machado AKF, Marmitt LP, Cesar JA. Prematuridade tardia no extremo sul do Brasil: um estudo de base populacional. Rev Bras Saúde Mater Infant. 2016;16(2):113-20.

15. Hentges CR, Guedes RR, Silveira RC, Procianoy RS. Serum levels of caffeine in umbilical cord and apnea of prematurity. J Pediatr (Rio J). 2010;86(2):137-42

16. Luz AG, Tiago DB, Silva JCG, Amaral E. Morbidade materna grave em um hospital universitário de referência municipal em Campinas, Estado de São Paulo. Rev Bras Ginecol Obstet. 2008;30(6):281-6.

17. Oliveiros Donohue MA, Chirinos Rivera J, Mayorga Ricalde G. Morbimortalidad del recién nacido de muy bajo peso y enfermedad hipertensiva del embarazo severa. Diagnóstico (Perú). 2003;42(3):103-6.

18. Benítez LRY, Bonneau GA, Castillo Rascón MS, López DL, Pedrozo WR Perfil lipídico por trimestre de gestación en una población de mujeres adultas. Rev Chil Obstet Ginecol. 2010;75(4):227-33.

19. Ghio A, Bertolotto A, Resi V, Volpe L, Di Cianni G. Triglyceride metabolism in pregnancy. Adv Clin Chem. 2011;55(1):133-53.
20. Callegari SB, Resende EA, Barbosa Neto O, Rodrigues Jr V, Oliveira EM, Borges MF. Obesity and cardiometabolic risk factors during pregnancy. Rev Bras Ginecol Obstet. 2014;36(10):449-55.

21. Oliveira LL, Gonçalves AC, Costa JS, Bonilha AL. Maternal and neonatal factors related to prematurity. Rev Esc Enferm USP. 2016;50(3):382-9.

22. Mudd LM, Holzman CB, Catov JM, Senagore PK, Evans RW. Maternal lipids at mid-pregnancy and the risk of preterm delivery. Acta Obstet Gynecol Scand. 2012;91(6):726-35.

23. Adamo KB, Ferraro ZM, Goldfield G, Keely E, Stacey D, Hadjiyannakis S, et al. The Maternal Obesity Management (MOM) Trial Protocol: a lifestyle intervention during pregnancy to minimize downstream obesity. Contemp Clin Trials. 2013;35(1):87-96.

24. Jelliffe-Pawlowski LL, Ryckman KK, Bedell B, O’Brodovich HM, Gould JB, Lyell DJ, et al. Combined elevated midpregnancy tumor necrosis factor alpha and hyperlipidemia in pregnancies resulting in early preterm birth. Am J Obstet Gynecol. 2014;211(2):141.e1-9.

25. Joy S, Istwan N, Rhea D, Desch C, Stanziano G. The impact of maternal obesity on the incidence of adverse pregnancy outcomes in high-risk term pregnancies. Am J Perinatol. 2009;26(5):345-9.

26. Berkowitz GS, Blackmore-Prince C, Lapinski RH, Savitz DA. Risk factors for preterm birth subtypes. Epidemiology. 1998;9(3):279-85.

27. Merzouk H, Madani S, Korso N, Bouchenak M, Prost J, Belleville J. Materna and fetal serum lipid and lipoprotein concentrations and compositions in type 1 diabetic pregnancy: relationship with maternal glycemic control. J Lab Clin Med. 2000;136(6):441-8.

28. Sebire NJ, Jolly M, Harris JP, Wadsworth J, Joffe M, Beard RW, et al. Maternal obesity and pregnancy outcome: a study of 287,213 pregnancies in London. Int J Obes Relat Metab Disord. 2001;25(8):1175-82.

29. Higa R, Jawerbaum A. Intrauterine effects of impaired lipid homeostasis in pregnancy diseases. Curr Med Chem. 2013;20(18):2338-50.

30. Crume TL, Shapiro AL, Brinton JT, Glueck DH, Martinez M, Kohn M, et al Maternal fuels and metabolic measures during pregnancy and neonatal body composition: the healthy start study. J Clin Endocrinol Metab. 2015;100(4):1672-80.

31. Watkins ML, Rasmussen SA, Honein MA, Botto LD, Moore CA. Maternal obesity and risk for birth defects. Pediatrics. 2003;111(5 Pt 2):1152-8.

32. Hull HR, Dinger MK, Knehans AW, Thompson DM, Fields DA. Impact of maternal body mass index on neonate birthweight and body composition. Am J Obstet Gynecol. 2008;198(4):416.e1-6. 